\title{
The Developing Intestinal Ecosystem: Implications for the Neonate
}

\author{
RICARDO A. CAICEDO, RICHARD J. SCHANLER, NAN LI, AND JOSEF NEU \\ Department of Pediatrics [R.A.C., N.L., J.N.], University of Florida, College of Medicine, Gainesville, \\ Florida 32610; Schneider Children's Hospital at North Shore [R.J.S.], North Shore University Hospital, \\ Manhasset, New York 11030; Albert Einstein College of Medicine [R.J.S.], Bronx, New York 10461
}

\begin{abstract}
ABST
Interactions of resident intestinal microbes with the luminal
contents and the mucosal surface play important roles in normal
intestinal development, nutrition, and innate and adaptive immu-
nity. The neonate, especially the premature, who possesses a
highly immunoreactive intestinal submucosa underlying a single
layer of epithelial cells that are continuously exposed to the
luminal environment, is highly susceptible to perturbations of the
luminal environment. Understanding the interactions of the in-
testinal ecosystem with the host and luminal nutritional environ-
ment, especially in regard to human milk and pre- and probiotics,
\end{abstract}
ABSTRACT

has major implications for the pathogenesis of diseases that affect not only the intestine but distal organs such as the lung and brain. (Pediatr Res 58: 625-628, 2005)
GI, gastrointestinal
LPS, lipopolysaccharide
NEC, necrotizing enterocolitis
TLR, toll-like receptor

Abbreviations
A better understanding of the developing intestinal ecosystem in the neonate may hold the key to prevention of several important diseases. This intestinal ecosystem is composed of three closely interacting components: host cells, nutrients, and microflora. Changes in intestinal microflora and host cells during maturation affect the developing intestine, and these interact with the changing nutrient environment. Reduction of normal commensal bacteria in the context of infection or after antibiotic treatment may interfere with availability of critical nutrients and impair beneficial stimulation of GI mucosal development and the innate and adaptive immune responses. Here we will briefly summarize some of our current knowledge about the intestinal microflora, its interaction with the maturing intestine, and the nutritional environment ("cross-talk"). We also discuss consequences of disrupted interaction between these components, especially pertaining to the intestinal mucosal inflammatory and immune capability, and why human milk is the appropriate substrate in this environment.

Received February 1, 2005; accepted May 25, 2005.

Correspondence: Josef Neu, M.D., Professor of Pediatrics, Divisions of Neonatology and Gastroenterology, Department of Pediatrics, College of Medicine, University of Florida, Box 100296, Gainesville, FL 32610; e-mail: neuj@peds.ufl.edu

DOI: 10.1203/01.PDR.0000180533.09295.84

\section{NORMAL MICROFLORA}

The microflora of the adult human is found primarily in the colon and distal small intestine and consists of more than $10^{13}$ microorganisms (the "microbiota"), comprising nearly 500 species and nearly 2 million genes (the "microbiome") (1). This is mostly a mutually beneficial relationship, as evidenced by the important role commensal bacteria play in nutrition (2), angiogenesis (3), and mucosal immunity $(4,5)$. The role of bacteria in providing nutrients to the host is exemplified by the fermentative salvage of lactose that remains unabsorbed in the distal intestine because of low lactase activities in the immature intestine of premature infants (6). The resulting short-chain fatty acids such as acetate, propionate, and butyrate are used for energy or synthetic processes (6), stimulate intestinal blood flow, affect intestinal proliferation and differentiation, and alter intestinal interepithelial tight junctions (7). Other beneficial effects of commensal bacteria include lipid hydrolysis, protein breakdown into peptides and amino acids, and vitamin production.

\section{DEVELOPMENT OF THE INTESTINAL MICROFLORA}

Marked changes occur in the intestinal microflora from birth to adulthood. At birth, the intestine is sterile but becomes 
rapidly colonized thereafter (8). Neonatal human intestine contains large numbers of facultative anaerobes such as Streptococcus and coliforms. These decline in number during weaning as obligate anaerobes such as Bacteroides and Clostridium establish a foothold and eventually become the predominant community residing in the gut. These changes are accompanied by transition from a high-fat, milk-based diet to a diet rich in carbohydrates and maternal immunoglobulins (8). In the preterm infant, the methods of neonatal intensive care, such as treatment with antibiotics, total parenteral nutrition, or nursing in incubators, may delay or impair the intestinal colonization process. They are thus slower to acquire commensals such as bifidobacteria and more susceptible to pathogenic colonization (9). The intestine of the premature infant also has poor motility and is predisposed to bacterial overgrowth (10).

Profound changes occur in the intestinal ecosystem when young mammals are weaned from their mother's milk. An example of such a change that normally occurs is in the angiogenins, potent antimicrobial peptides released from the Paneth cells of the crypt (11). In mice raised in a conventional environment, angiogenin mRNA expression is markedly increased at the time of weaning from mother's milk to an adult diet. This change occurs to a much lesser degree in germ-free mice $(11,12)$. It is also thought that commensal bacteria, through "cross-talk" and the production of angiogenins, are critical for normal villus capillary development. One dramatic example of this is seen in the lag in development of the villus capillaries in the mouse small intestine grown in a germ-free environment versus normal growth in an environment containing normal mixed flora or even only one species of commensal bacterium (Bacteroides thetaiotaomicron) (3).

\section{ROLE OF MICROFLORA IN INFLAMMATION}

The commensal microflora may represent a key regulatory checkpoint for the intestinal inflammatory response. The intestinal epithelium partially relies on TLR to act as an interface between the luminal microflora and signal transduction pathways. TLR are cell-surface receptors that recognize specific microbial ligands, from both pathogens and commensals, enabling the innate immune system to recognize nonself, and activating both innate and adaptive immune responses (13). Studies of the interaction between resident microflora and TLR are beginning to shed light on how the healthy intestinal surface defuses the threat of commensal bacteria to the lumen, and how this interaction is actually required to maintain the architectural integrity of the epithelium $(14,15)$. These studies suggest that the epithelium and resident immune cells do not simply tolerate commensal microorganisms but are dependent on them. Commensal bacteria secrete molecules such as LPS and lipoteichoic acid, which in turn interact in the normal intestine with a population of surface TLR. The resultant ongoing signaling enhances the ability of the epithelial surface to withstand injury while also priming the surface for enhanced repair responses. Therefore, either the disruption of TLR signaling or the removal of TLR ligands compromises the ability of the intestinal surface to protect and repair itself in the face of inflammatory or infectious insult (5). Another study reported nonvirulent Salmonella strains whose direct interaction with model human epithelia attenuate IL-8 production elicited by various proinflammatory stimuli (16). This interaction abrogates the polyubiquitin-mediated degradation of the inhibitor of nuclear factor kappa-B (alpha subunit; $\mathrm{I} \kappa-\mathrm{B} \alpha$ ) (16). These studies raise intriguing questions: Is the TLR signaling pathway fully functional in the premature infant? Does the common practice of treating premature infants with broad-spectrum antibiotics shortly after birth adversely affect the commensal population? Does the lack of enteral nutrition or the provision of commercial formula rather than mother's milk result in undergrowth of commensal bacteria?

The microbial population of the developing GI tract of the premature infant affects maturation and optimal function of the intestinal innate and adaptive immune system, suggesting a pathogenic role in several diseases related to systemic inflammation such as NEC, chronic lung diseases, intraventricular hemorrhage, periventricular leukomalacia, and hematopoietic abnormalities. Over the past few years, a body of literature has emerged supporting that overproduction of IL-8 is a critical, and arguably the most important, component of the systemic inflammatory response in neonates. The role of IL-8 in chorioamnionitis, intracerebral hemorrhage, and lung disease is compelling (17-21). High concentrations of IL-8 are frequently noted in the plasma and affected tissues of patients who exhibit these problems. This leukocyte chemoattractant chemokine, which can be produced in large quantities by the intestine, has thus been causally linked to some of these problems, implying that modulation of intestinal production of IL-8 may be a key to prevention. It is notable that infant intestine appears to be much more sensitive to stimuli, such as LPS and flagellin that induce IL-8, than is adult intestine $(22,23)$. Figure 1 represents a hypothetical scheme as to how commensal microorganisms or probiotic bacteria might interact with the intestine to prevent these complications.

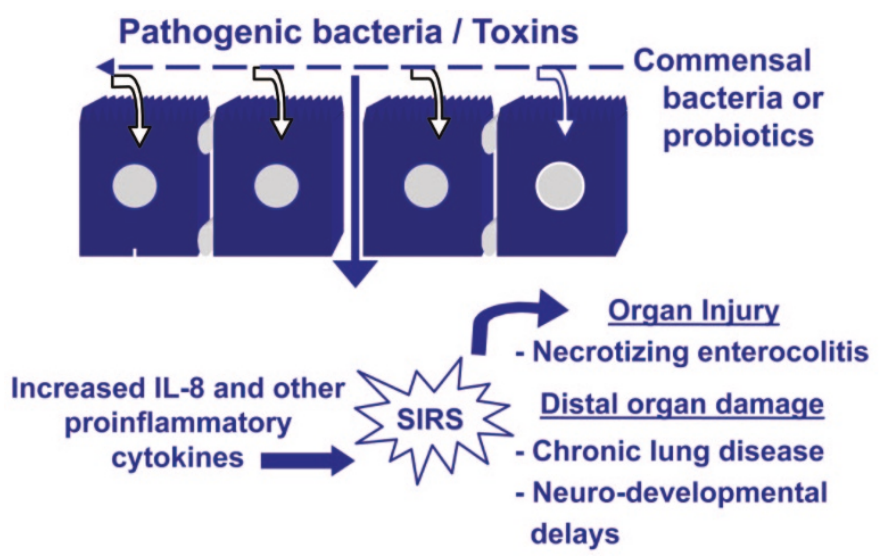

Figure 1. Hypothetical scheme demonstrating the effect of commensal microorganisms on the intestinal production of proinflammatory mediators such as IL-8 and the subsequent prevention of propagation of this inflammatory mediator to proximal (intestine) as well as distal organs (lung and brain). 


\section{ENTERAL NUTRIENTS, HUMAN MILK, AND THE INTESTINAL MICROFLORA}

Nutrients, as well as probiotic bacteria and/or prebiotics (nutritional substrates that promote the growth of probiotic bacteria), through their stimulation of a normal commensal microflora may also play an important role in the regulation of IL-8 (24-27) and neutrophil infiltration into the intestine. The reliance on parenteral nutrition while providing few or no enteral nutrients may be highly significant in the promotion of intestinal inflammation because the presence of enteral nutrients can prevent gut-derived inflammation (28). Whether this is partially due to stimulation of commensal bacterial growth is speculative. Several in vitro studies have shown that probiotics (live, heat-killed, and DNA from probiotic bacteria) can downregulate intestinal IL-8 production $(26,27,29-31)$ induced by proinflammatory stimuli such as LPS, but studies in neonatal animals (in vivo) showing regulation of intestinal inflammation by pre- or probiotics have not yet been published.

The feeding of human milk is an immediate way to promote the development of the intestinal ecosystem in the neonate, including the preterm. The beneficial effects generally relate to improvements in host defenses, digestion and absorption of nutrients, GI function, neurodevelopmental outcomes, and maternal psychological well-being and also may contribute to a reduction in the economic burden brought on by the long hospitalization of the premature infant. However, the special needs of the preterm infant that arise as a result of metabolic and GI immaturity, immunologic compromise, and associated medical conditions must be considered so that adequate nutrition can be provided to meet the needs for intrauterine rates of growth and nutrient accretion (32).

Clinical studies in nurseries throughout the world indicate that premature infants have fewer episodes of late-onset sepsis, NEC, diarrhea, and urinary tract infection, and need less antibiotic therapy when fed their own mothers' milk compared with similar infants fed formula (33-35). Although the greater the dose of human milk, the greater the protective effects, reductions in the incidence of late-onset sepsis and/or NEC occur in infants who only receive partial mother's milk feedings ( $>50 \mathrm{~mL} / \mathrm{kg}$ ) compared with similar infants fed either less mother's milk or preterm formula $(36,37)$. A recent report indicated that $30 \%$ of mothers of extremely premature infants did not secrete the anti-inflammatory cytokine IL-10 in their milk, yet this cytokine was not found in $85 \%$ of the mothers whose milk was fed to similar infants who developed NEC (38). The presence of high concentrations of soluble CD14 (sCD14), a pattern recognition receptor molecule not found on the intestinal surface, in human milk is also of interest in this regard. sCD14 prevents inflammatory conditions of the gut and has been shown to induce B-cell growth and differentiation (39). This is especially intriguing because of previously reported studies that show that breast-feeding combined with providing probiotics to mothers and their infants is associated with a decreased development of atopic diseases as these children get older (40).

Human milk contains a wide array of biologically active components. The growth of pathogenic bacteria and viruses is known to be inhibited by proteins like lactoferrin, secretory $\operatorname{IgA}$, and peptide formed from human milk during digestion (41). Human milk is an important factor in the initiation, development, and composition of the neonatal gut microbiota. It has been found to be a significant source of lactic acid bacteria that appear to be of endogenous origin and not contaminants from the breast skin (42). Some of these bacteria belong to the species Lactobacillus, the probiotic potential of which has recently been evaluated (43). The lactobacilli isolated from milk of healthy mothers is at least similar to that of the strains commonly used in commercial probiotic products in terms of survival to GI tract conditions, production of antimicrobial compounds, adherence to intestinal cells, production of biogenic amines, and patterns of antibiotic resistance. Among the numerous substances present in human milk, oligosaccharides have a clear prebiotic effect, stimulating the development of bifidogenic flora in the colon (44). Breast-fed infants, unlike those who are formula- fed, have an intestinal ecosystem characterized by a strong prevalence of bifidobacteria and lactobacilli $(8,9)$. Human milk can be considered a symbiotic (44), a substance that has the properties of both a pro- and prebiotic. Other anti-inflammatory components in human milk include antioxidants, epithelial growth factors, cellular protective agents, and enzymes that degrade mediators of inflammation (45). Although the above-mentioned microbes found in milk may be partially responsible in reducing infection and inflammation, the lower $n-6 / n-3$ fatty acid ratio, through a higher relative concentration of the anti-inflammatory $n-3$ compared with proinflammatory n- 6 fatty acids, may also play a role (46). Lastly, there is some indication that host-defense benefits persist even beyond hospitalization in former premature infants. Fewer upper respiratory signs and symptoms were reported when human milk was continued after discharge, even if the diet was only partial human milk, and the protective effects continued even beyond the time human milk feeding was discontinued (47).

The relationship between human milk and reduced incidence of sepsis and/or NEC reported in the above studies may have important economic implications. For example, a reduction in the incidence of NEC may have profound effects on the cost of health care. It has been reported that one case of medically treated NEC increases the cost of hospitalization by $\$ 73,700$ (48). Given conservative estimates of the incidence of NEC, a $10 \%$ versus $4 \%$ incidence of NEC in formula- versus human milk-fed premature infants means that 5600 versus 2240 infants might be affected in the United States (2002 statistics), with a cost differential of $\$ 4.1$ million versus $\$ 1.6$ million (49).

\section{CONCLUSIONS}

Establishment and maintenance of a "normal" intestinal microflora may help abrogate several neonatal inflammatory conditions that not only affect the GI tract but are initiated in the gut and cause damage to distal organs such as the lung and brain. Decreasing excessive use of antibiotics and increasing the use of pro- and prebiotics or symbiotic nutrients such as human milk that promote the establishment and growth of a 
beneficial microflora are means by which neonatologists can maintain their patients' intestinal ecosystem.

\section{REFERENCES}

1. Xu J, Gordon JI 2003 Honor thy symbionts. Proc Natl Acad Sci U S A 100:1045210459

2. Hooper LV, Midtvedt T, Gordon JI 2002 How host-microbial interactions shape the nutrient environment of the mammalian intestine. Annu Rev Nutr 22:283-307

3. Stappenbeck TS, Hooper LV, Gordon JI 2002 Developmental regulation of intestinal angiogenesis by indigenous microbes via Paneth cells. Proc Natl Acad Sci U S A 99:15451-15455

4. Neish AS 2002 The gut microflora and intestinal epithelial cells: a continuing dialogue. Microbes Infect 4:309-317

5. Rakoff-Nahoum S, Paglino J, Eslami-Varzaneh F, Edberg S, Medzhitov R 2004 Recognition of commensal microflora by toll-like receptors is required for intestinal homeostasis. Cell 118:229-241

6. Kien CL 1996 Digestion, absorption, and fermentation of carbohydrates in the newborn. Clin Perinatol 23:211-228

7. Sanderson IR 2004 Short chain fatty acid regulation of signaling genes expressed by the intestinal epithelium. J Nutr 134:2450S-2454S

8. Bourlioux P, Koletzko B, Guarner F, Braesco V 2003 The intestine and its microflor are partners for the protection of the host: report on the Danone Symposium "The Intelligent Intestine," held in Paris, June 14, 2002. Am J Clin Nutr 78:675-683

9. Saavedra JM 2001 Clinical applications of probiotic agents. Am J Clin Nutr 73:1147S-1151S

10. Gracey M 1982 Intestinal microflora and bacterial overgrowth in early life. J Pediatr Gastroenterol Nutr 1:13-22

11. Hooper LV, Stappenbeck TS, Hong CV, Gordon J 2003 Angiogenins: a new class of microbicidal proteins involved in innate immunity. Nat Immunol 4:269-273

12. Hooper LV 2004 Bacterial contributions to mammalian gut development. Trends Microbiol 12:129-134

13. Takeda K, Kaisho T, Akira S 2003 Toll-like receptors. Annu Rev Immunol 21:335376

14. Madara J 2004 Building an intestine-architectural contributions of commensal bacteria. N Engl J Med 351:1685-1686

15. Strober W 2004 Epithelial cells pay a Toll for protection. Nat Med 10:898-900

16. Neish AS, Gewirtz AT, Zeng H, Young AN, Hobert ME, Karmali V, Rao AS, Madara JL 2000 Prokaryotic regulation of epithelial responses by inhibition of IkappaB-alpha ubiquitination. Science 289:1560-1563

17. De Dooy J, Mahieu L, Van Bever H 2001 The role of inflammation in the development of chronic lung disease in neonates. Eur J Pediatr 160:457-463

18. Kohse KP, Carl A, Steinbach G 2002 Whole blood interleukin- 8 concentrations in capillary and cord blood of neonates for the diagnosis of systemic inflammatory states. Clin Lab 48:497-503

19. Shalak L, Laptook A, Jafri H, Ramilo O, Perlman J 2002 Clinical chorioamnionitis, elevated cytokines, and brain injury in term infants. Pediatrics 110:673-680

20. Tauscher M, Berg D, Brockmann M, Seidenspinner S, Speer C, Groneck P 2003 Association of histologic chorioamnionitis, increased levels of cord blood cytokines, and intracerebral hemorrhage in preterm neonates. Biol Neonate 83:166-170

21. Yoon B, Park C, Chaiworapongsa T 2003 Intrauterine infection and the development of cerebral palsy. BJOG 110:124-127

22. Claud EC LL, Anton PM, Savidge T, Walker WA, Cherayil BJ 2004 Developmentally regulated IkappaB expression in intestinal epithelium and susceptibility to flagellin-induced inflammation. Proc Natl Acad Sci U S A 101:7404-7408

23. Nanthakumar NN, Fusunyan RD, Sanderson I, Walker WA 2000 Inflammation in the developing human intestine: a possible pathophysiologic contribution to necrotizing enterocolitis. Proc Natl Acad Sci U S A 97:6043-6048

24. Liboni K, Li N, Neu J 2004 Mechanism of glutamine-mediated amelioration of lipopolysaccharide-induced IL-8 production in Caco-2 cells. Cytokine 26:57-65

25. Liboni KC, Li N, Scumpia PO, Neu J 2005 Glutamine modulates LPS-induced IL-8 production through IkappaB/NF-kappaB in human fetal and adult intestinal epithelium. J Nutr 135:245-25
26. Ma D, Forsythe P, Bienenstock J 2004 Live Lactobacillus reuteri is essential for the inhibitory effect on tumor necrosis factor alpha-induced interleukin-8 expression. Infect Immun 72:5308-5314

27. Bai AP, Ouyang Q, Zhang W, Wang CH, Li SF 2004 Probiotics inhibit TNF-alphainduced interleukin-8 secretion of HT29 cells. World J Gastroenterol 10:455-457

28. Kudsk KA 2002 Current aspects of mucosal immunology and its influence by nutrition. Am J Surg 183:390-398

29. Jijon H, Backer J, Diaz H, Yeung H, Thiel D, McKaigney C, De Simone C, Madsen K 2004 DNA from probiotic bacteria modulates murine and human epithelial and immune function. Gastroenterology 126:1358-1373

30. Rachmilewicz D, Katakura K, Karmeli F, Hayashi T, Reinus C, Rudensky B, Akira S, Takeda K, Lee J, Takabayashi K, Raz E 2004 Toll-like receptor 9 signaling mediates the anti-inflammatory effects of probiotics in murine experimental colitis. Gastroenterology 126:520-528

31. Petrof EO, Kojima K, Ropeleski MJ, Musch MW, Tao Y, De Simone C, Chang EB 2004 Probiotics inhibit nuclear factor-kappaB and induce heat shock proteins in colonic epithelial cells through proteasome inhibition. Gastroenterology 127:14741487

32. Ziegler EE, O'Donnell AM, Nelson SE, Fomon SJ 1976 Body composition of the reference fetus. Growth 40:329-341

33. Hylander MA, Strobino DM, Dhanireddy R 1998 Human milk feedings and infection among very low birth weight infants. Pediatrics 102:E38

34. Kashyap S, Ohira-Kist K, Abildskov K, Towers HM, Sahni R, Ramakrishnan R, Schulze K 2001 Effects of quality of energy intake on growth and metabolic response of enterally fed low-birth-weight infants. Pediatr Res 50:390-397

35. Lucas A, Cole TJ 1990 Breast milk and neonatal necrotising enterocolitis. Lance 336:1519-1523

36. Furman L, Taylor G, Minich N, Hack M 2003 The effect of maternal milk on neonata morbidity of very low-birth-weight infants. Arch Pediatr Adolesc Med 157:66-71

37. Schanler RJ, Shulman RJ, Lau C, Smith EO, Heitkemper MM 1999 Feeding strategies for premature infants: randomized trial of gastrointestinal priming and tube-feeding method. Pediatrics 103:434-439

38. Fituch CC, Palkowetz KH, Goldman AS, Schanler RJ 2004 Concentrations of IL-10 in preterm human milk and in milk from mothers of infants with necrotizing enterocolitis. Acta Paediatr 93:1496-1500

39. Filipp D, Alizadeh-Khiavi K, Richardson C, Palma A, Paredes N, Takeuchi O, Akira S, Julius M 2001 Soluble CD14 enriched in colostrum and milk induces B cell growth and differentiation. Proc Natl Acad Sci U S A 98:603-608

40. Kalliomaki M, Salminen S, Arvilommi H, Kero P, Koskinen P, Isolauri E 2001 Probiotics in primary prevention of atopic disease: a randomised placebo-controlled trial. Lancet 357:1076-1079

41. Lonnerdal B 2004 Human milk proteins: key components for the biological activity of human milk. Adv Exp Med Biol 554:11-25

42. Martin R, Langa S, Reviriego C, Jiminez E, Marin ML, Xaus J, Fernandez L, Rodriguez JM 2003 Human milk is a source of lactic acid bacteria for the infant gut J Pediatr 143:754-758

43. Martin R, Olivares M, Marin ML, Fernandez L, Xaus J, Rodriguez JM 2005 Probiotic potential of 3 Lactobacilli strains isolated from breast milk. J Hum Lact 21:8-17

44. Coppa GV, Bruni S, Morelli L, Soldi S, Gabrielli O 2004 The first prebiotics in humans: human milk oligosaccharides. J Clin Gastroenterol 38:S80-S83

45. Goldman AS, Ogra PL 1999 Anti-infectious and infectious agents in human milk. In Ogra PL, Mestecky J, Lamm ME, Strober W, Bienenstock J, McGhee JR (eds) Mucosal Immunology. Academic Press, San Diego, CA, pp 1511-1521

46. Hanson LA, Korotkova M, Telemo E 2003 Breast-feeding, infant formulas, and the immune system. Ann Allergy Asthma Immunol 90:59-63

47. Blaymore Bier JA, Oliver T, Ferguson A, Vohr BR 2002 Human milk reduces outpatient upper respiratory symptoms in premature infants during their first year of life. J Perinatol 22:354-359

48. Bisquera JA, Cooper TR, Berseth CL 2002 Impact of necrotizing enterocolitis on length of stay and hospital charges in very low birth weight infants. Pediatrics 109:423-428

49. Arias E, MacDorman MF, Strobino DM, Guyer B 2003 Annual summary of vita statistics-2002. Pediatrics 112:1215-1230 